\title{
LO QUE NO PUEDE SER DICHO. UNA LECTURA ESTÉTICA EN EMMANUEL LEVINAS
}

\section{DanieLle Cohen-LeVInAs}

En memoria de Jacques Rolland

Mi lectura de los escritos de Emmanuel Levinas no es ni erudita ni docta, ni se halla en sincronía con la historia de la filosofía. Ella es como una intromisión, una especie de deuda para con aquel que me condujo progresivamente, durante largos años, a escuchar de otro modo la cuestión de la obra de arte y, a través de deslizamientos ostensibles, de la música. Paradoja de esta singular escucha, cuyo origen me cuidaré de no presentar aquí, es que ella me fue transmitida por un filósofo que no ha situado explícitamente la estética en el centro de sus preocupaciones, a excepción de la literatura y la poesía, a las que a él gustaba designar con la expresión "mis experiencias pre-filosóficas", y también a excepción de una mirada habitada sobre algunos artistas'.

Esta lectura está cogida en la elipse de esa incesante atención que él prestaba al arte, una proximidad a la vez respetuosa y vigilante. Era necesario para él mantener una distancia con la cuestión artística, un intervalo en el cual se pudiese percibir una inquietud, quizá incluso una desconfianza identificable con sus silencios o sus propósitos y escritos enrarecidos. El arte musical representaba para él el dominio privilegiado de su esposa Raïsa, pianista, y de su hijo, Michaël, pianista y compositor.

Siempre estupefacta, asombrada, inquieta por saberme ligada intelectualmente a esta disciplina, me preguntaba a menudo, como en un momento de 
verificación cuasi filosófica, si yo no había cedido aún a una forma de melancolía de la que la música está cargada. Yo comprendía esta pregunta como el paradigma mismo de su inquietud; la escuchaba bajo el tono de la queja, una letanía especulativa que me remitía a la precariedad del discurso, de su logos, de sus marcos normativos, lejos de aquello que Hegel llamaba los Oh y los Ah del alma.

La distancia a la cual hice referencia, la difícil articulación entre la ética y la estética supone un conocimiento de ambas, pero también, y de manera más paradójica, el retiro de una respecto de la otra, la conciencia de una ruptura o de una cesura como acto de vigilancia a la vez histórico y crítico. Habría en Levinas un aplazamiento de la cuestión estética que la convierte en indisociable de su obra, tendida hacia un en otro lugar, según su expresión, del cual yo diría que está voluntariamente enrarecido, pues se halla encerrado a su vez en la elipse dramática del antes y el después de Auschwitz.

No es cierto, como algunos lo piensan y a veces lo escriben, que su filosofía haya decididamente desertado del arte y la estética. No me corresponde enumerar la cantidad de sus escritos consagrados a esta cuestión tan neurálgica, incluido lo no dicho, lo no escrito y lo no registrado. Tres de sus textos arrojan un verdadero anatema sobre esta percepción completamente reductible: $L a$ réalité et son ombre (La realidad y su sombra) ${ }^{2}$; dieciséis años más tarde, en 1964, en La signification et le sens (La significación y el sentido) ${ }^{3}$ Levinas expresará afinidades convergentes y divergentes con Merleau-Ponty; en 1974, en Autrement qu'être ou au-delà de l'essence (De otro modo que ser o más allá de la esencia $)^{4}$, retomará una reflexión dejada en suspenso en La realidad y su sombra.

Levinas se pregunta sobre la naturaleza de los vínculos entre lenguaje y arte, entre el filósofo y el artista y, más aun, entre el filósofo y el arte; habría una autoridad externa, la obra, que sería asimilable a un tercero, dotado de no

2 Publicado por primera vez en Les temps modernes en 1948. [CF. la traducción al español de Antonio Domínguez Leiva en Trotta, Madrid, 200I. N. de los T.].

3 Publicado en Revue de métaphysique et de morale en 1964 y retomado ulteriormente en Humanisme de l'autre homme, ed. Fata Morgana, Paris, 1974. [Cf. la traducción al español de Graciano González-Arnáiz en Caparrós Editores, Madrid, 1993. N. de los T.].

${ }^{4}$ Cf. la traducción al español de Antonio Pintor Ramos en Sígueme, Salamanca, 2003 (N. de los T.). 
palabra, un tercero desprovisto de lenguaje o, más exactamente, un tercero cuya palabra no se juega en ningún responsable ${ }^{5}$, en ninguna dirección significante. De allí la desconfianza frente al discurso sobre o en torno a la obra de arte. De allí la desconfianza respecto de la estética. Si, como Levinas lo entiende en La realidad y su sombra, el arte no es un lugar de compromiso, en el sentido adorniano del término, sino de desprendimiento ${ }^{6}$, en el sentido que no llama a respuesta ni pide un complemento a través del verbo, entonces esta autoridad externa será siempre como intocable e intocada por la mirada que la atraviesa o por la palabra que intenta aproximarse a ella. Levinas explica que el arte no hace signo, "como no hace signo el hombre mudo que encuentro", escribe Guy Petitdemange, "cuyo silencio parece siempre anunciar la tormenta o la mañana de una palabra posible"7.

Esta concepción de la obra de arte es relativamente clásica. Se trata de la idea según la cual lo propio de la obra es su acabamiento; obra como totalidad replegada sobre sí misma, cuyo sentido coincide con la forma; ideal hegeliano que conduce a aquello que Levinas expresa sucintamente así: "ninguna palabra más por añadir, ninguna palabra más por suprimir”. Como si la obra tuviera por finalidad desprenderse del mundo y erigirse en un soliloquio absoluto, cuya precariedad es tal que subraya incesantemente su desvanecimiento en

\footnotetext{
5 Cohen-Levinas emplea aquíla palabra "répondant". Forma nominal tomada del verbo "répondre" (responder), esta palabra designaba, en su uso original (fines del siglo XVII), a aquel que debía responder a las objeciones en la sustentación de una tesis ("L'argumentant et le répondant") así como, durante el siglo XVIII, se usaba en el ámbito católico para referirse a quien, durante la misa, debía responder a los pedidos del celebrante. Hemos optado aquí por el término español "responsable" (responder a alguien y por la vida de alguien, ser "respondiente" y responsable a la vez) que sitúa bien la filosofía del lenguaje levinasiana en el marco de la reflexión ética: responder es responder a alguien y, en este sentido, ser responsable de aquel en quien la palabra es ya, siempre, solicitud de respuesta, dirección hacia el otro. Esta acepción corresponde, por lo demás, al uso de "répondant" en el francés actual tanto en frases como "être le répondant de quelqu'un" ("ser responsable de alguien") como en el sentido de persona que se hace garante de otra: "Je veux te présenter moi-même, et te servir de répondant" (Lesage) ("Yo mismo quiero presentarte y servirte de garante"). Cf. Rey, Alain, Josette Rey-Debove y Paul Robert, Le petit nouveau Robert de la langue francaise, París: Le Robert, 2009, p. 2201 (N. de los T.).

6 El término que emplea Levinas es "dégagement" en el sentido de liberación o desprendimiento que, en el caso del arte, conduce no al "au delà" (más allá) como huella del paso del Infinito en el rostro-llamado a la responsabilidad y al diálogo, ética- sino al "en decà" (más acá) de un tiempo interrumpido por la estructura formal de acabamiento que caracteriza toda imagen -hechizo en el eterno presente de una imagen siempre fija y muda, estética. Cf. "La réalité et son ombre", en: Les imprévus de I'histoire, Montpellier: Fata Morgana, 1994, p. 126 (N. de los T.).

7 Cf. "L'art, ombre de l'être ou voix vers l'autre? Un regard philosophique sur l'art d'Emmanuel Levinas”, en: Revue d'Esthétique, Jean-Michel Place, Paris.
} 
relación con el lenguaje. Ella estaría siempre en situación de consentimiento y no de soberanía.

Parece, además, que esta concepción fuera testimonio o sería corolario de una crítica subyacente en la filosofía estética por parte de Levinas. Las teorías estéticas en vigor hasta el final del siglo XIX tropiezan con una dificultad principal: se hallan en la imposibilidad de tratar sobre el arte recurriendo a un sistema de categorías filosóficas que, por lo demás, dependen tradicionalmente de las teorías del conocimiento que les sirven de presupuestos. En este sentido, Levinas coincide con Adorno: las grandes estéticas filosóficas están en concordancia con el arte, tanto que reducen al concepto su carácter de evidente universalidad. El hecho, por ejemplo, de que un mismo espíritu reine en la filosofía y en el arte permite a la primera tratar de una manera sustancial al segundo sin entregarse a las obras. De allí el hecho de que Levinas concluya el conjunto de sus consideraciones sobre el arte, en 1948, por la invocación del lenguaje -del lenguaje sobre el arte; dicho de otro modo, de la crítica y de la exégesis filosófica. Estas indican de entrada una preeminencia del verbo sobre la imagen $y$, a través del deslizamiento de singularidades, podríamos deducir que subrayan en filigrana, y siempre en el terreno de lo no dicho, una preeminencia del sonido sobre la imagen. En esta época, Levinas, al igual que Adorno, condena un arte que constituiría, según él, "en un mundo de la iniciativa y de la responsabilidad, una dimensión de evasión”. Para el Adorno de la Teoría estética, toda la felicidad estética se reduce al placer de la disonancia: sensación negativa que evoca, sin admitirlo, la dicha de una reconciliación que hoy el arte se prohíbe para no servir de apología del mundo tal cual es. Por hoy hay que comprender en el presentimiento y en la antecámara de Auschwitz y de su porvenir sin llamado. Un porvenir, dirá Adorno, "que no responde a la cuestión de saber cómo llenar el abismo entre la realidad actual del arte y el arte como promesa de felicidad". Hay que religar este arte que no responde o que ya no responde más a aquel de Levinas, palabra cerrada a toda réplica, a toda "interrupción" por el discurso.

De modo que uno es llevado a preguntarse dónde está la singularidad del arte en Levinas. ¿Dónde reside esta singularidad del en otro lugar que no es ni la evasión ni la toma de poder? ¿Qué dice esta singularidad y cómo escucharla una vez descartada la idea kantiana, entre la indeterminación de lo bello y la idea estética que acerca el arte a la filosofía; una vez desechada la idea post 
kantiana según la cual la estética debe de abordar, a su manera, los problemas fundamentales de la filosofía y, llegado el caso, ofrecerles una solución; una vez descartada la búsqueda de la superación de la subjetividad por el ideal de una ciencia de lo bello o del arte; y una vez desechada la práctica estética como interpretación de la sucesión de las obras consideradas como significados o como reveladoras por una filosofía de la historia?

En Levinas no hay ninguna dimensión de llamado propia de la obra de arte y, sobre todo, no existe el llamado de lo bello, el llamado de la belleza, categoría estética por excelencia. El arte, escribe Levinas en La realidad y su sombra, "es el acontecer mismo del oscurecimiento, un caer de la noche, una invasión de la sombra". Sería un fenómeno de reflujo, el encuentro con la afasia, el verbo mudo. ¿Qué queda todavía por decir después de la cosa artística, después del acontecimiento artístico? Levinas coincide con Adorno. ¿Cómo producir arte después de Auschwitz? ¿Cómo escribir un poema? ¿Cómo pensar lo bello, representarlo, contarlo, traducirlo, leerlo, escucharlo, hacerlo hablar, cantar, sonar? El arte es una experiencia del desapego y de la desposesión; desposesión de sí y desposesión de la historia. Exclusión del concepto y, por consiguiente, suspensión del relato.

Quisiera introducir aquí otra referencia que no me parece ajena a esta sensibilidad estética, a la vez radical y trágica. Para el Levinas de La realidad y su sombra, la soberanía del arte sería aquella de la muerte; es lo sin palabra, lo sin responsable ${ }^{8}$, lo sin emisor, lo sin receptor. Uno puede, en efecto, preguntarse si más allá de la muerte como síntoma de la soberanía del arte no habría una muerte anunciada del arte, o al menos aplazada, hasta De otro modo que ser, que sería en definitiva una muerte anunciada y/o del relato, de aquello que el arte cuenta, de aquello que nos cuenta, más que de aquello que él se cuenta.

Quisiera evocar un instante la interpretación que Ricœur realiza del texto de Walter Benjamin, “Der Erzähler”, publicado con el título Le narrateur (El narrador) en Walter Benjamin. Poésie et révolution (Poesía y revolución) ${ }^{9}$. Se trata de un texto redactado entre 1935 y 1940, traducido por Maurice de Gandillac, pero del que existe una traducción al francés del mismo Benjamin,

"Le sans répondant". Cf. la quinta nota de los traductores (N. de los T.).

9 Denoël, 197I. 
revisada por un corrector desconocido y entregada, en 1939, a las manos de Adrienne Monier. Benjamin expresa en "Der Erzähler" el temor que los hombres experimentan de vivir el fin de una era en la cual el lugar y la función del relato son cuestionados, incluso reducidos a la nada. Él explica cómo todos los narradores han bebido de una experiencia transmitida de boca en boca; y cómo después la muerte es la sanción de todo lo que puede relatar el narrador ${ }^{10}$. Ricœur constata el temor de Benjamin a través de los comentarios sobre la muerte de Nicolas Leskov (nacido en I83I, muerto en (891): "Y sin embargo... y sin embargo... quizá hay que confiar a pesar de todo en el pedido de concordancia que estructura aún hoy la expectativa de los lectores y creer que nuevas formas narrativas que no sabemos nombrar todavía están ya en proceso de nacer, formas que atestiguarán que la función narrativa puede metamorfosearse pero no morir. Pues no tenemos idea alguna sobre aquello que sería una cultura en la cual ya no se supiese lo que significa narrar".

El relato, como laboratorio de formas, y de formas narrativas pero igual y esencialmente como laboratorio del tiempo. Sabemos que para Ricœur la narración manifiesta tanto más sus límites cuanto no siempre consigue responder a las aporías de la temporalidad. Esto es lo que expresa la situación intermedia del relato, entre lo descriptivo y lo prescriptivo, entre una fenomenología o una analítica y una ética.

Para Levinas, el discurso filosófico sobre el arte está cargado igualmente de mediaciones: es la relación con el tiempo. Un tiempo sin espacio, un tiempo de fuga, "el tiempo en un presente imposible", según la expresión de JeanLuc Nancy". La aporética de un tiempo en concordancia, de un tiempo que coincide, provoca para Levinas un aplazamiento del juicio estético; aplazamiento gracias al cual el mundo y la conciencia acceden a la dimensión temporal de la obra.

El arte está íntegramente asociado al tiempo; al otro tiempo, que no es, como se podría creer, una imagen de eternidad, sino su contrario, su negativo: a saber, el destino. Lo que Levinas considera como el adversario absoluto, más

10 Temps et récit, vol. II, Paris, Seuil, p. 48.

"Le poids d'une pensée, 1992. 
acá de toda palabra; destino al cual están sometidos tanto el artista como el juicio estético. Del mismo modo que en la tragedia antigua anterior a Eurípides, particularmente en Esquilo, el curso de los acontecimientos y del relato, el curso de las cosas, el curso del mundo pueden ser interrumpidos en todo momento por la irrupción siempre estrepitosa del coro, el arte instala una diacronía en el curso mismo de la sincronía del relato, del mundo y del tiempo; y es por ello que el arte no aclara en nada la historia; $y$ es debido a esto que el arte está "liberado"'2, según la expresión de Levinas, de toda luz, de todo conocimiento, de toda resistencia y combate por la libertad. Es un lugar de enmarañamiento y para el enmarañamiento. "El comercio con lo oscuro", escribe Levinas, "como acontecimiento ontológico totalmente independiente, ino describe categorías irreductibles a las del conocimiento?"

Estos decires y estos no dichos se apoyan sobre la manera como se efectúa para Levinas el trabajo propio del arte; el trabajo del arte, se podría sugerir, implica una ruptura epistemológica permanente; $y$ en 1948 el trabajo del arte para Levinas es esencialmente productor de imágenes: "El procedimiento más elemental del arte", escribe, "consiste en sustituir el objeto por su imagen".

Ahora bien, para Levinas, la imagen excluye el concepto. Se podría decir que, con el surgimiento de la imagen, el concepto se fija, se convierte en un ícono del pensamiento y de la actividad filosófica. Levinas anticipa un horizonte no verbal por venir. No ceder a la melancolía doliente del arte, a su poder de oscurecimiento, al de la música en particular, pues el precio a pagar sería fatal: la pérdida de la escucha, la pérdida de la intelección esencial de los afectos y del entendimiento. No ceder al famoso y clásico desinterés de la visión artística, pues acabaríamos por caer en la ceguera; en la ceguera respecto de los conceptos, y en consecuencia, respecto del lenguaje.

La imagen es un lugar de representación mágica, mortuoria, ella nos domina puesto que apaga nuestra vigilancia y nos retira la iniciativa al retirarnos la palabra. Crítica de la imagen, crítica de la fenomenología que reduce la imagen y desconoce su opacidad, pues la opacidad es supuesta por la

12 “Dégagé”. Cf. la sexta nota de los traductores (N. de los T.). 
semejanza que caracteriza la imagen. Para Levinas, la semejanza implica, o al menos supone, una interrupción del pensamiento, una ceguera y una sordera del pensamiento sobre la imagen y, así pues, una verdadera opacidad de esta. De allí la idea filosófica, pero igualmente poética, según la cual la realidad, a través del movimiento de la semejanza, suscita secretamente sus propias imágenes: "la realidad”, escribe Levinas, "no sería solamente aquello que es, aquello que se devela en la verdad, sino también su doble, su sombra, su imagen".

Henos aquí en la encrucijada tan compleja y latente del arte, del destino, de la inseguridad, lo que yo llamo el efecto de paganismo y de idolatría intrínseco a la actividad artística. Todo aquello que cae presa del destino pertenece al arte. "Otra vez", escribe Levinas, "conviene relacionar arte y sueño: el instante de la estatua y la pesadilla". Se piensa en la estatua del convidado de piedra en Don Juan de Mozart. ¿Es una ficción, el artificio de una verdad, lo reverso del concepto? Entrar en el destino es ser representado; "pero", añade Levinas, "eso es precisamente la obra de arte, acontecimiento del oscurecimiento del ser paralelo a su revelación, a su verdad”.

Un punto esencial es anotado en La realidad y su sombra: la filosofía del arte, la estética, debe hacer intervenir la relación con el otro, "sin la cual el ser no sabría ser dicho en su realidad, en su tiempo”, escribe Levinas.

La cuestión de la exégesis será objeto de análisis en De otro modo que ser. El arte, la obra de arte, pictórica, musical o poética, hace resonar proposiciones predicativas, y la estética, o al menos la exégesis, consiste en escucharlas, comprenderlas, descubrirlas. La estética sería, entonces, una palabra que acompaña a la obra de arte, "metalenguaje no eliminable”. “La exégesis”, escribe Levinas, "no se adhiere a la resonancia de la esencia en la obra de arte. La resonancia de la esencia vibra al interior de lo dicho de la exégesis”. En De otro modo que ser, el lenguaje es intrínseco a la obra de arte, quizá de manera inesperada pero pronta a acoger la vibración del arte. ¿Es esto una forma de canto, la queja que urde el lenguaje? La estética no es más un discurso venido de afuera, como una palabra extraña a la obra. Es una fuerza de actualización. Hace explícito lo que está implícito. 
No únicamente la representación, la plasticidad, la imagen de la obra, sino igualmente su soporte, y yo diría su materialidad, comienza a hacer resonar su esencia y, escribe Levinas, "a partir del arte, ostensión por excelencia".

El arte se convierte aquí sobre todo en un lugar de insomnio filosófico, un ámbito que mantiene en vigilia al concepto y le impide caer, precipitarse en el destino. "Es la búsqueda de formas nuevas de la que vive todo arte alerta y que soporta los verbos, a punto de recaer en sustantivos".

Temporalización del arte por el verbo, y quizá incluso condición narrativa del arte por el verbo, incluidos los momentos en los que este arte se "produce como contornos", expresión de Levinas, y "devienen vacantes gracias a su vacuidad de formas".

Levinas tenía una concepción más bien platónica de la música, del mismo modo que en el Banquete, en el momento en el que los protagonistas deben ponerse de acuerdo para dedicarse a la verdadera filosofía, aparece el flautista, aquel que encarna una presencia de deshumanización y de desfiguración por el simple hecho de que su boca está ocupada en producir sonidos y no en pronunciar palabras. La música sería demasiado espectral, como si quisiera tener la última palabra. Como si la tuviese. Con Michaël, su hijo, a su lado, y algunos otros compositores provenientes de la clase Messiaen, Levinas vio nacer una de las principales corrientes de la creación musical de la mitad del siglo XX: la corriente llamada espectral. Me parece que es esta idéntica espectralidad lo que Levinas ha escuchado en Nomos Alpha de lannis Xenakis; "el violoncelo que violoncelisa" es el paradigma mismo del tiempo de la obra expresada en el material.

El sonido sería un material de lo dicho que no se borra ante aquello que evoca. Más aun, aquello que evoca cede el lugar a aquello que representa, y lo que representa es su pura materialidad. Tautología del arte que consiste en dominar los procedimientos musicales a través de la materialidad del instrumento, a través de sus funciones vibratorias y resonantes que en música se llaman sonidos inarmónicos y parciales: dicho de otro modo, el espectro del sonido. La ofensiva del sonido es un efecto de la realidad exterior de lo musical. Lo que resuena es su doble; sus vibraciones infinitesimales más elocuentes en su 
abstracción que la representación acústica puramente formal. La narración se ha deslizado hacia el narrador.

El vínculo con Adorno es explícito. El arte vive en y por su material, cuyas exigencias contrarían por adelantado toda institucionalización, toda tentativa de reducción por medio del lenguaje. Los conceptos adornianos de modelo y de constelación, rebeldes a toda fijación, provienen igualmente de la experiencia musical. En ese sentido, el ritmo del pensamiento en Adorno permanece innegablemente ligado a su objeto, a tal punto que aquel no puede dar cuenta sino de la relación que guarda con este.

"El ideal platónico consistiría en hacer superflua la justificación de aquello que uno hace haciéndolo".

Quisiera volver a la queja. La queja, y no la melancolía doliente que evocaba al inicio. A diferencia del lenguaje cuyas palabras zanjan a veces sin equívoco alguno, la música aplaza el juicio, aplaza la decisión, o la explicación. Ciertamente, el lenguaje es la condición primera de la queja. Pues en el fondo, si se le diera el lenguaje, si se lo prestáramos, no estoy lejos de pensar que la obra de arte se quejaría a través de él. ¿Y de qué se quejaría? Sin duda del lenguaje. De allí un extraordinario avance de Levinas, quien, entre 1948 y 1974, pasa ostensiblemente de una crítica de la obra de arte como entidad absolutamente autónoma frente al lenguaje, incluso autoritaria, a su llamado a una concepción en la que la obra es un arrancamiento ${ }^{13}$; arrancamiento al lenguaje y, en consecuencia, una emanación más o menos cercana o lejana de la queja. Toda queja se arranca. El sonido se arranca a la cuerda; el color, al lienzo; la poesía, a la palabra. La queja se mantiene en el umbral del lenguaje, allí donde el lenguaje simultáneamente comienza y acaba; allí donde se produce el sentido. O más exactamente, allí donde pasa.

Siempre he comprendido lo que dice Levinas como ese momento neurálgico del paso del sentido, ese momento en el cual el sonido, por definición infralingüístico y totalmente desprovisto de sentido, hace escuchar su materialidad. Reflexión estética, reflexión sobre lo musical que no es, que no es más la

13 Preferimos "arrancamiento" a "desprendimiento", porque la primera recoge mejor la fuerza del término "arrachement" (N. de los T.). 
expresión de lo inexpresable, o de lo inefable, cara a Vladimir Jankélévitch, o de un orden superior. Lo musical ya no es únicamente esta fuerza que desata las subjetividades, esta representación sensible de un contenido insensible. Es lo musical, la vibración que nace de la interrupción del sentido, del arrancamiento al lenguaje; de la inversión cuasi dialéctica de las ocurrencias; de un contenido que desborda el continente y lo arrastra consigo. Sobre esto es necesario que meditemos.

Traducción de Raphael Aybar y Cesare del Mastro 